\title{
Rare-earth elements in groundwater of the abandoned Levikha copper mine (Middle Urals, Russia)
}

\author{
Petr A. Rybnikov ${ }^{1, *}$, and Liudmila S. Rybnikova ${ }^{1}$ \\ ${ }^{1}$ The Institute of Mining, Ural Division of the Russian Academy of Sciences, Mamin-Sibirjak str. 58, \\ 620075, Ekaterinburg, Russia
}

\begin{abstract}
The distribution of REE in groundwater of the catchments, which were formed during the long-term operation of copper mines in the Middle Urals (Russia), was studied. The groundwater composition reflects a significant removal of REE from water-bearing rocks, which leads to their enrichment by several orders of magnitude relative to the oceans, surface water and groundwater. Maximum REE values (up to $15 \mathrm{mg} / \mathrm{L}$ ) were recorded in groundwater discharged to the surface in the collapse zone $(\mathrm{pH}=3.5)$. In mine shafts REE values do not exceed $0.3 \mathrm{mg} / \mathrm{L}$. Water of mine wastes occupy an intermediate position: here REE content varies from 0.5 to $6.5 \mathrm{mg} / \mathrm{L}$. The degree of REE fractionation in mine waters is lower than in oceanic, surface and underground waters of the active water exchange zone at much higher contents. The chemical composition of groundwater of the abandoned copper mine is determined by hypogene processes and structure of the mineralized supergene zone, its mineralogical composition, and oxidation-reduction conditions.
\end{abstract}

\section{Introduction}

The distribution analysis of rare earth elements (REE) allows insight into the nature of processes occurring in different geochemical media [1-5]. REE are a highly coherent group of elements whose concentrations in rocks, soils, surface and groundwater due to their close chemical properties and similarity of behavior are indicators of rock sources and physicochemical processes. Properties of cerium and europium are sensitive to changes in the oxidation-reduction conditions of natural processes. Absolute values of REE concentrations have a significant spread, therefore, normalization of the concentrations to one of several possible rock standards produces a smooth curve, the analysis of which makes it possible to assess the type of processes and the fractionation of elements during these processes. Normalization on North American Shale Composite (NASC) was used [5].

The main source of rare earth elements in the ocean is considered to be suspended and dissolved river runoff. Suspended river discharge of the REE composition may reflect the composition of the rocks of the catchment area of the river, but the greater basin and diversity of species it represents, the more the suspended matter composition is reminiscent

\footnotetext{
${ }^{*}$ Corresponding author: ribnikoff@yandex.ru
} 
of platforms' schist or clay. The REE distribution in ocean waters, normalized to NASC, is characterized by very low values and a large range of changes (from $10^{-9}$ to $10^{-6}$ ), in addition, in ocean waters there is a clear tendency of heavy REE enrichment and negative anomaly of cerium. Analysis of the normalized REE distribution in several major rivers of the world shows a rather smooth curve in a small range from $10^{-6}$ to $10^{-5}$ and weak enrichment with heavy REE [6]. For fresh groundwater of the active water flow zone of the Russian Far East it was found that the range of normalized REE values is larger, from $10^{-6}$ to $10^{-3}$ [4]. There is a negative cerium anomaly and a positive europium. We have studied the REE distribution of groundwater of the catchments that was disturbed in the process of long-term mining of copper deposits in the Middle Urals [7].

\section{Case studies and methods}

The object of this study is the abandoned Levikha mine. The exploitation continued for almost 80 years and ended in 2003. The group of Levikha bearing massive sulphide deposits are located $120 \mathrm{~km}$ to the north from Ekaterinburg in the valley of the river Tagil (the Ob'-Irtysh basin, Arctic Ocean). Geochemical type of deposits is copper-zinc; mineralogical composition of ores: pyrite, chalcopyrite, sphalerite, bornite, faded ores, pyrrhotite, magnetite, galena, chalcocite, covellite, and native gold. The features of Levikha deposits are the large number of ore bodies (about 100 have beenmined, total amount about 800 ) and an abundance of interspersed ores that surround the bodies of massive pyrites. The main types of ore-bearing rocks are schists - quartz-sericite and quartz-chlorite.

The hydrochemical and geoecological hazards in the area of the Levikha mine are currently determined by several sources: flooded mine shafts (up to $618 \mathrm{~m}$ deep), flooded pits (up to $70 \mathrm{~m}$ deep), a zone of concentrated discharge of mine waters (collapse zone of about $30 \mathrm{~m}$ deep, with a volume of about 50 thousand $\mathrm{m}^{3}$ ), waste rocks (with a volume of 3.5 million $\mathrm{m}^{3}$ ) containing sulfides and heavy metals, mine waste waters, purification pond, discharge from the pond in the Tagil River, and discharge of surface and groundwater in the Tagil River from the catchment area. The work is based on the results of detailed hydrochemical studies at the facility [7]. Since the release of groundwater to the surface in April 2007, the mine waters of the discharge zone have been analysed on a daily basis. The $\mathrm{pH}$ and concentrationsof $\mathrm{Cu}^{2+}, \mathrm{Zn}^{2+}, \mathrm{Fe}_{\text {tot }} \mathrm{Mn}^{2+}, \mathrm{As}^{2+}, \mathrm{SO}_{4}{ }^{2-}$, TDS, and suspended matter are determined. In addition, we regularly perform extended laboratory studies of major and trace element composition of water samples. Samples were taken during the low-flow period to avoid dilution. The concentration of 70 components was determined using the methods of inductively-coupled plasma mass spectrometry (ICP-MS). Temperature, Eh, $\mathrm{pH}$, TDS were measured in situ.

For the analysis of REE distribution in samples, normalization with respect to North American Shale Composite (NASC) was used [5]. For the characteristics of light REE lanthanum was used, for medium REE gadolinium was used, and for heavy rare earth elements ytterbium was used. To calculate the europium anomaly, the expression $\mathrm{Eu} / \mathrm{Eu}^{*}=\log \left(2 \mathrm{Eu}^{*} /\left(\mathrm{Sm}^{*}+\mathrm{Gd}^{*}\right)\right.$ was used, where $\mathrm{Eu}^{*}, \mathrm{Sm}^{*}, \mathrm{Gd}^{*}$ are concentrations of europium, samarium and gadolinium normalized to NASC. To calculate the europium anomaly, the expression $\mathrm{Ce} / \mathrm{Ce}^{*}=\log \left(2 \mathrm{Ce}^{*} /\left(\mathrm{La}^{*}+\mathrm{Pr}^{*}\right)\right)$ was used, where $\mathrm{Ce}^{*}, \mathrm{La}^{*}, \mathrm{Pr}^{*}$ are cerium, lanthanum and praseodymium concentrations normalized to NASC [3; 4].

\section{Results and discussion}

The anionic composition of all waters investigated on Levikha field are strongly dominated by sulfate, their cationic composition is mixed iron-aluminum-magnesium. Their 
mineralization is maximal for the waters of the discharge zone and for the mine wastes waters - from 10 to $50 \mathrm{~g} / \mathrm{L}$. In mine shafts, mineralization does not exceed $0.5 \mathrm{~g} / \mathrm{L}$. According to the acid-alkaline conditions the samples in the discharge zone and in mine shafts are acidic ( $\mathrm{pH}$ from 3 to 5), mine wastes water is strongly acidic (pH 2.5). The Eh of the solution is about $250 \mathrm{mV}$ for discharge zone waters and mine shafts, in mine wastes waters it is $550 \mathrm{mV}$.

The REE concentration varies over a very wide range: high values from 3.5 to 15.3 $\mathrm{mg} / \mathrm{L}$ are observed in the discharge zone, the range of $0.5-$ to $6.5 \mathrm{mg} / \mathrm{L}$ is found in the mine wastes waters, and the values in the mine shafts are one to two orders of magnitude lower $(0.005$ to $0.3 \mathrm{mg} / \mathrm{L}$, Table 1$)$. Correlation analysis showed that the rare earth elements are most closely associated with magnesium $\left(R^{2}=0.97\right)$, zinc $\left(R^{2}=0.91\right)$, manganese $\left(R^{2}=0.83\right)$, and iron $\left(\mathrm{R}^{2}=0.82\right)$. Usually REE concentrations are several orders of magnitude lower $(0.08$ to $1.01 \mu \mathrm{g} / \mathrm{L})$ in surface and fresh groundwater [4], and $0.003 \mu \mathrm{g} / \mathrm{L}$ in ocean water [3]. Such abnormally high concentrations of REE in dissolved form (from 0.4 to $16 \mathrm{mg} / \mathrm{L}$ ) were recorded as a result of the formation of acidic sulfate waters in the oxidation zone of sulfide ores of the gold-polymetallic Berezite deposit in the Far East of Russia, and copper deposits of the Iberian pyrite belt $[2,8]$.

For all groups of tested objects, the concentration of light REE (cerium group) is about three times higher than heavy (ytterbium group), light REE is 64 to $85 \%$ of the total REE. The ratio of $\mathrm{La}^{*} / \mathrm{Yb}^{*}$, which also characterizes the behavior of light and heavy REE, is characterized by significant variations, 0.05 to 0.76 for the discharge zone, 0.45 to 1.59 for mine shafts, 0.46 to 0.70 for waste rock waters (Table 1, Fig.1).

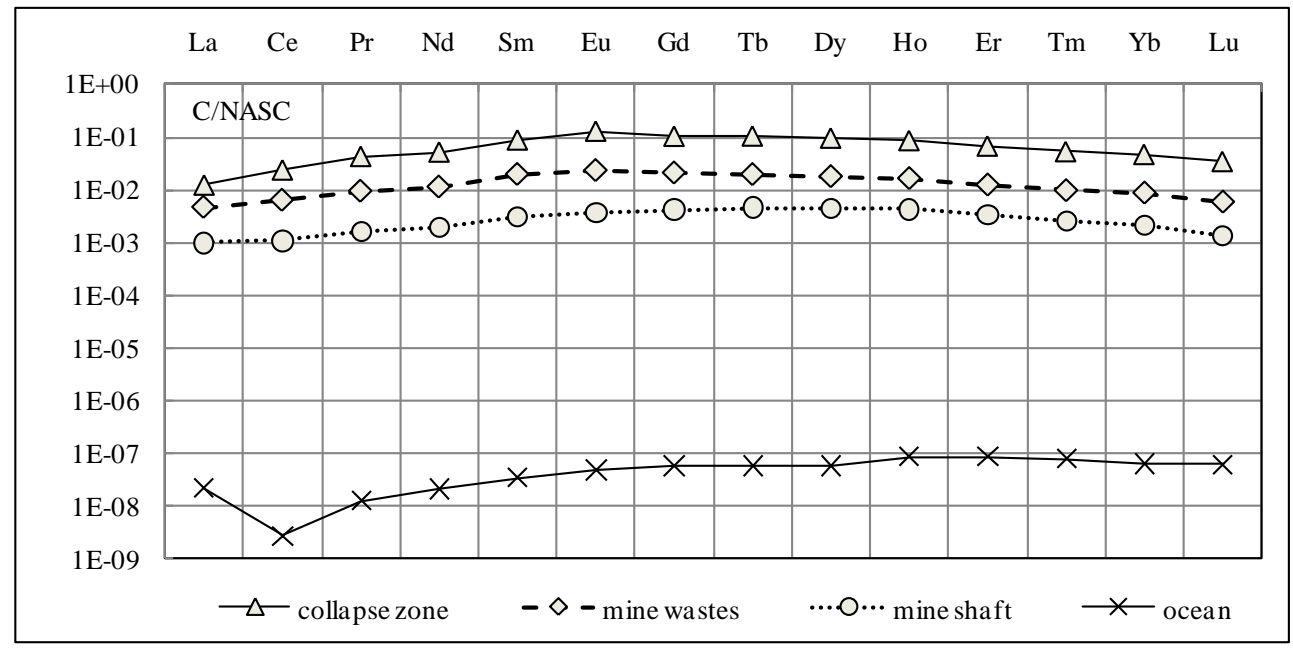

Fig. 1. Average NASC-normalized ratios of rare earth elements in groundwater of the supergene zone (Levikha field) and in the ocean.

Most of the studied samples are characterized by a small positive anomaly of europium in the range of 0.02 to 0.16 . The exception is the sample from the North shaft, where the anomaly is negative and $\mathrm{Eu} / \mathrm{Eu}^{*}$ varies from -0.02 to -0.11 . The cerium anomaly in all samples is negative and varies from 0 to -0.07 for the discharge zone, from -0.05 to -0.11 for mine shafts, from -0.04 to -0.05 for mine waste waters.

The shape of the REE distribution curves in the waters of the discharge zone has not changed since 2008, they are characterized by a well-pronounced rise in the region of the light REE and a smooth decrease in the region of heavy REE. The same regularities are established for mine waste waters at lower absolute values of REE. For water samples taken 
from mine shafts, the maximum normalized values of REE are shifted to the group of medium and heavy REE. The degree of REE fractionation in mine waters is lower than in oceanic, surface and underground waters of the active water exchange zone (Fig. 1).

Table 1. Distribution of rare-earth elements in groundwater of the supergene zone of the Levikha copper deposit.

\begin{tabular}{|c|c|c|c|c|c|c|}
\hline \multirow[b]{2}{*}{ Sampling point } & \multirow[b]{2}{*}{ Date } & \multicolumn{5}{|c|}{ Characteristics } \\
\hline & & $\begin{array}{c}\sum \mathrm{REE} \\
\mu \mathrm{g} / \mathrm{L}\end{array}$ & $\begin{array}{c}\text { LREE } \\
\mu \mathrm{g} / \mathrm{L}\end{array}$ & $\begin{array}{c}\text { HREE } \\
\mu \mathrm{g} / \mathrm{L}\end{array}$ & $\begin{array}{c}\text { LR } \\
\% \\
\end{array}$ & $\begin{array}{c}\mathrm{HR} \\
\%\end{array}$ \\
\hline \multicolumn{7}{|c|}{ Discharge zone } \\
\hline Caving & 2007 & 11,803 & 9,348 & 2,455 & 79 & 21 \\
\hline Caving & 2008 & 15,316 & 11,561 & 3,755 & 75 & 25 \\
\hline Caving & 2010 & 5,090 & 3,997 & 1,093 & 79 & 21 \\
\hline Caving & 2013 & 6,526 & 4,884 & 1,642 & 75 & 25 \\
\hline Caving & 2014 & 4,792 & 3,588 & 1,204 & 75 & 25 \\
\hline Caving & 2016 & 4,337 & 3,261 & 1,075 & 75 & 25 \\
\hline Caving & 2017 & 3,513 & 2,634 & 0,879 & 75 & 25 \\
\hline \multicolumn{7}{|c|}{ Shafts } \\
\hline Levikha XIV & 2008 & 0,073 & 0,055 & 0,018 & 75 & 25 \\
\hline Levikha XIV (depth 30 m) & 2013 & 0,284 & 0,211 & 0,074 & 74 & 26 \\
\hline Levikha XIV (depth 40 m) & 2013 & 0,285 & 0,211 & 0,074 & 74 & 26 \\
\hline Levikha XIV (depth 50 m) & 2013 & 0,286 & 0,212 & 0,074 & 74 & 26 \\
\hline Levikha XII & 2008 & 0,050 & 0,037 & 0,013 & 74 & 26 \\
\hline North shaft (depth 40 m) & 2013 & 0,004 & 0,003 & 0,001 & 79 & 21 \\
\hline North shaft (depth 50 m) & 2013 & 0,005 & 0,004 & 0,001 & 85 & 15 \\
\hline \multicolumn{7}{|c|}{ Mine wastes } \\
\hline Collapse zone & 2014 & 1,527 & 1,210 & 0,317 & 79 & 21 \\
\hline Mine wastes waters & 2014 & 6,536 & 5,042 & 1,495 & 77 & 23 \\
\hline Mine wastes waters & 2017 & 0,514 & 0,423 & 0,091 & 82 & 18 \\
\hline
\end{tabular}

\section{Conclusion}

The mine water enrichment by REE in relation to other natural waters are determined by their hydrogeochemistry. Part of REE is concentrated in accessory minerals such as zircon, monazite or allanite. These minerals are not easily weathered, and therefore are concentrated in clastic rocks and placers. Most REE in igneous and sedimentary rocks are in rock-forming silicates, such as plagioclase, apatite. Weathering of these minerals occurs due to $\mathrm{CO}_{2}$ and humic acids. Once in solution, REE in the pore water are in the form of trivalent cations or with neutral and alkaline $\mathrm{pH}$, in the form of a complex with $\mathrm{CO}_{3}{ }^{2-}$ and $\mathrm{OH}^{-}$. Due to the positive charge and ionic potential, trivalent cations are sorbed by the negatively charged surface of clays, kaolinite and illite or replace $\mathrm{Na}^{+}$and $\mathrm{Ca}^{2+}$ in smectites $[6,8]$.

As a result, REE are mainly concentrated in clays, which become the main reservoir of $\mathrm{REE}$ in sedimentary rocks. If the primary rock is rich in REE, weathering clays can become 
a source for mining, as residual (eluvial) deposits in southern China [8]. However, in the systems containing acid mine water, the rate of aluminosilicates dissolution increases. Once in the solution, REE mainly migrate in the form of $\mathrm{REESO}_{4}{ }^{+}$. Complexation of sulfates inhibits the sorption of REE in clays and stabilizes them in solution. As a result, the concentration of REE in mine waters is much higher than in other natural waters.

Analysis of REE distribution and fractionation in the flooded Levikha mine indicate the different mechanisms for the formation of chemical composition of groundwater in the supergene zone: in the area of discharge and the mine wastes on the one hand and in mine shafts on the other. At the same time, the formation of all types of mine waters is accompanied by a significant removal of REE from water-bearing rocks, which leads to their enrichment with rare-earth elements by several orders of magnitude higher than in the ocean, surface and groundwater.

The assessments has shown that the potential recoverable value of non-ferrous metals and rare-earth elements in mine waters exceeds the cost of ensuring annual neutralization of acidic waters entering rivers and exceeds the amount of environmental damage from the discharge of treated mine waters [9]. Groundwater of flooded copper mines may be considered as renewable deposits of water mineral raw materials. Potential resources of REE (the estimated total mass removal for 25 years) is about 120 t. The recoverable value will be about 130 million USA \$ [9].

The studies were performed in the framework of fundamental research programme of the RAS (No. 0405-2018-0015, No. 0405-2015-0011).

\section{References}

1. L.P. Alekseeva, Geochemistry of underground ice, salt water and brines of Western Yakutia, Tomsk, 43 (2016)

2. E.A. Vakh, Rare earth elements in natural and man-made waters of the Russian Far East, Vladivostok, 22 (2012)

3. A.V. Dubinin, Geochemistry of rare earth elements in the ocean, Moscow, 359 (2006)

4. N.A. Kharitonova, E. A. Vakh, G.A. Chelnokov, O.V. Chudaev, I.A. Aleksandrov, I.V. Bragin, Tikhookeanskaja Geologija 35, 2, 16 (2016)

5. L.P. Gromet, R.F. Dymek, L.A. Haskin, R.L. Korotev, Geochim. et Cosmochim. Acta. 48, 12, 15 (1984)

6. J. Gaillardet, J. Viers, B. Dupré, Treatise on geochemistry, 2nd edn. Elsevier, Oxford, (2014)

7. L.S. Rybnikova, P.A. Rybnikov, Procedia Earth and Planetary Science 17, 4 (2017)

8. C. Ayora, F. Macías, E. Torres, J.M. Nieto, XXXV Reunión de la Sociedad Española de Mineralogía Huelva, 22 (2015)

9. L.S. Rybnikova, P.A. Rybnikov, Vodnoje khoziajstvo Rossiji, 1, 14 (2016) 